\title{
Characterization of Bacterial Communities in Breeding Waters of Anopheles darlingi in Manaus in the Amazon Basin Malaria-Endemic Area
}

\author{
Louise K. J. Nilsson ${ }^{1,2}$ (1) Marta Rodrigues de Oliveira ${ }^{3} \cdot$ Osvaldo Marinotti $^{4} \cdot$ Elerson Matos Rocha ${ }^{5,6}$. \\ Sebastian Håkansson ${ }^{7}$ - Wanderli P. Tadei ${ }^{3,6}$. Antonia Queiroz Lima de Souza ${ }^{3,8}$ - Olle Terenius ${ }^{1,2}$
}

Received: 21 May 2018 / Accepted: 19 March 2019 / Published online: 15 April 2019

(C) The Author(s) 2019

\begin{abstract}
The microbiota in mosquito breeding waters can affect ovipositing mosquitoes, have effects on larval development, and can modify adult mosquito-gut bacterial composition. This, in turn, can affect transmission of human pathogens such as malaria parasites. Here, we explore the microbiota of four breeding sites for Anopheles darlingi, the most important malaria vector in Latin America. The sites are located in Manaus in the Amazon basin in Brazil, an area of active malaria transmission. Using 16S rRNA gene sequencing by MiSeq, we found that all sites were dominated by Proteobacteria and Firmicutes and that $94 \%$ of the total number of reads belonged to 36 operational taxonomic units (OTUs) identified in all sites. Of these, the most common OTUs belonged to Escherichia/Shigella, Staphylococcus, and Pseudomonas. Of the remaining 6\% of the reads, the OTUs found to differentiate between the four sites belonged to the orders Burkholderiales, Actinomycetales, and Clostridiales. We conclude that An. darlingi can develop in breeding waters with different surface-water bacteria, but that the common microbiota found in all breeding sites might indicate or contribute to a suitable habitat for this important malaria vector.
\end{abstract}

Keywords Microbiota $\cdot$ Amazonas $\cdot$ Malaria $\cdot$ Anopheles darlingi $\cdot$ Mosquito $\cdot 16 \mathrm{~S}$ rRNA

\section{Introduction}

The Amazon tropical rainforest contains $\sim 25 \%$ of the world's terrestrial biodiversity [1]. Along with the many species of plants, insects, mammals, and birds, microorganisms abound and their diversity is still unknown. In recent years in many

Electronic supplementary material The online version of this article (https://doi.org/10.1007/s00248-019-01369-9) contains supplementary material, which is available to authorized users.

Olle Terenius

olle.terenius@icm.uu.se

1 Department of Cell and Molecular Biology, Microbiology, Uppsala University, P.O. Box 596, 75124 Uppsala, Sweden

2 Department of Ecology, Swedish University of Agricultural Sciences (SLU), P.O. Box 7044, 75007 Uppsala, Sweden

3 Programa de Pós-graduação em Biotecnologia e Recursos Naturais da Amazônia, Universidade do Estado do Amazonas,

Manaus, AM 69065-001, Brazil

4 Department of Molecular Biology and Biochemistry, University of California, 3205 Mc-Gaugh Hall, Irvine, CA 92697, USA parts of the world, extensive research has been performed on the diversity and function of environmental microbial communities and the microbiota associated with humans, animals, and plants [2-6]. It is now known that these microorganisms contribute to nutrient cycling, food webs, detoxification, and the wellbeing of plants, animals, and ecosystems [7]. One

5 Programa de Pós-graduação em Biotecnologia, Universidade Federal do Amazonas, Manaus, AM, Brazil

6 Laboratório de Malária e Dengue, Instituto Nacional de Pesquisas da Amazonia, Manaus, AM 69011-970, Brazil

7 Uppsala BioCenter. Department of Molecular Sciences, Swedish University of Agricultural Sciences (SLU), P.O. Box 7025, 75007 Uppsala, Sweden

8 Faculdade de Ciências Agrárias, Universidade Federal do Amazonas (FCA/UFAM), Manaus, AM 69080-900, Brazil 
example where the microbiota plays an important role is in the development of mosquito larvae because mosquito larvae feed on microorganisms and in particular on bacteria in their breeding water $[8,9]$. Several studies have even shown that bacteria are indispensable for mosquito development. For example, as early as 1935, Rozeboom [10] showed that Aedes aegypti could not develop in bacteria-filtered water. Touré et al. [11] observed large larval mortality in water treated with antibiotics and Coon et al. [12] showed that axenic larvae failed to develop past first instar. Furthermore, bacteria have been shown to both attract $[13,14]$ and repel [15] gravid mosquitoes to potential breeding sites, suggesting they direct ovipositing females. Besides affecting oviposition and development of larvae, the bacteria in the breeding water might also impact the microbiota of the adult mosquitoes, as adult mosquitoes have been shown to contain gut bacteria found in their breeding water $[12,16,17]$. Moreover, the gut bacteria in adult mosquitoes have been correlated to pathogen survival in the mosquitoes. For example, a Chromobacterium sp. ( $C s p_{-} P$ ) has been shown to increase resistance to infection of both Dengue virus in Ae. aegypti and the malaria-causing agent Plasmodium falciparum in Anopheles gambiae [18], and an Enterobacter sp. (Esp_Z) has been shown to increase resistance to P. falciparum in An. gambiae [19]. Genetic modification of mosquito gut bacteria has also been suggested as a tool to prevent malaria transmission by producing antiparasitic molecules in the mosquito gut [20].

The mosquito An. darlingi is the principal malaria vector in the Amazon basin [21], responsible for 875,000 cases of malaria per year on the American continent [22]. While research has been conducted on the microbiota of breeding waters of malaria vectors from the Old World, in rice paddies, seminatural and natural habitats in Kenya [23-25], breeding sites in Iran [26], natural habitats in Cameroon [17], and domestic water-storage containers in India [27], very little is known about the microorganisms associated with the breeding waters of malaria vectors on the South American continent. As a matter of fact, the number of publications concerning bacteria associated with An. darlingi is very limited. Thus far, one study by Rejmankova et al. [28] investigated the number of bacteria classified as cocci or rods associated with larval habitats of four species of Anopheles in Belize. They showed that overall cocci were most common and there was some difference in number of cocci and rods between some of the habitats with different Anopheles species. However, the bacteria were not classified further. In a pilot study on An. darlingi adults, Terenius et al. [29] obtained 56 16S rRNA gene sequences from six host-seeking mosquitoes. All of these belonged to Gammaproteobacteria, where sequences closely related to Enterobacter, Pantoea, Aeromonas, and Pseudomonas were most abundant. In a recent study of the feces of An. darlingi, culture-based methods identified five genera of bacteria belonging to the classes Gammaproteobacteria and Bacilli [30]. A recent study on gut bacteria in two Colombian malaria vectors, An. darlingi and An. nuneztovari, showed that the most important determinants of gut bacteria composition was developmental stage followed by geographical location [31]. These two determinants were more important than mosquito species or adult feeding status.

Anopheles larvae are filter feeders that use their head brushes to feed on particles found in the surface microlayer (SML) [32]. The SML has chemical and biological properties that differ greatly from the water a few centimeters below surface. The Anopheles larvae are not selective feeders, but typically, the size of the particles ingested is less than $50 \mu \mathrm{m}$ [32], which means that bacteria belong to the food commonly ingested. In this study, our objective was to characterize the bacterial community composition in the SML of $A n$. darlingi breeding waters. To do this, we used MiSeq sequencing of $16 \mathrm{~S}$ rRNA gene amplicons from four $A n$. darlingi breeding sites in Manaus, Brazil. While different habitats may result in location-driven variability in bacterial composition, it has also been shown that in the same type of habitats, the presence of certain groups of bacteria is correlated with the presence of mosquito larvae (see, e.g., [27]). We therefore hypothesized that either certain species or larger taxonomic groups of bacteria (up to community level) and the conditions they indicate would be similar in all sites as the sites are comparable in size and characterized by large abundances of An. darlingi larvae.

\section{Methods}

\section{Water Sampling}

Surface water was collected from four water bodies in the Manaus municipality (Table 1, Online Resource Fig. A.1a), an area of active malaria transmission. The four collection sites located in Manaus are permanent Anopheles breeding sites as determined by the Vigilância Epidemiológica da Secretaria Municipal de Saúde de Manaus [Epidemiological Surveillance of the Municipal Health Secretariat in Manaus]. At each of the four collection sites, samples were obtained from four equidistant sub-sites, approximately $5 \mathrm{~m}$ from each other, on the lake/dam/fish tank perimeter (Online Resource Fig. A.1b.). Surface water samples $(900 \mathrm{~mL})$ were collected in the morning at 8:30 AM using a hand-dipper and stored on ice in sterile flasks for transportation. In the laboratory, each water sample was filtered through three overlaid filters (filter paper Whatman grade 4, and millipore membranes of $0.45 \mu \mathrm{m}$ and $0.22 \mu \mathrm{m}$; Online Resource Fig. A.1b). The retained material was eluted from each filter in $2 \mathrm{~mL}$ of distilled and autoclaved water and centrifuged for $12 \mathrm{~min}$ at $10,000 \mathrm{~g}$. The supernatant was discarded and the pellet DNA extracted. Twelve samples 
Table 1 Geographic location and characteristics of the Anopheles darlingi breeding sites where water was collected. Maps and additional information about the sites are found in Supplementary Fig. A.1 and Supplementary information A.1

\begin{tabular}{llllll}
\hline \multirow{2}{*}{ Site } & Location & Characteristics & GPS coordinates & Collection date (Month/year) \\
\cline { 3 - 6 } & & & Latitude (S) & Longitude (W) \\
\hline 1 & Puraquequara-Portela & Lake with small fish, shaded edges & 03 03. 081' & $059^{\circ} 53.594^{\prime}$ & $01 / 2013$ \\
2 & Puraquequara-Estrada do Brasileirinho & Dam, no fish, vegetation in margins & $03^{\circ} 01.190^{\prime}$ & $059^{\circ} 54.700^{\prime}$ & $03 / 2013$ \\
3 & Puraquequara-Sítio do Carlão & Fish tank, no vegetation & $03^{\circ} 02.770^{\prime}$ & $059^{\circ} 52.874^{\prime}$ & $04 / 2013$ \\
4 & AM 010-Extension of Sítio Canarinho & Lake with fish, vegetation in margins & $02^{\circ} 53.730^{\prime}$ & $059^{\circ} 54.969^{\prime}$ & $04 / 2013$ \\
\hline
\end{tabular}

were DNA extracted per site, originating from three filters from each of the four sub-sites per collection site (Online Resource Fig. A.1b). Thus, in total, 48 samples were DNA extracted.

\section{DNA Extraction of Water Samples and 16S rRNA Gene Amplification by PCR}

To obtain the total DNA from the water samples, DNA extractions were performed by first lysing the cells by heat shock of the pellets from the filtrates. Then, the innuPREP Plant DNA kit (Analytik Jena) was used following the manufacturer's protocol. The handling of biological material from the Amazon region is strictly regulated. To avoid bringing any material (including genomic DNA) from Manaus to our laboratory facilities in Sweden, we performed a first-step PCR in Manaus. In order to not affect the downstream processes, we started with primers outside the target region V3-V4. Recovered DNA was thus dissolved in $20 \mu \mathrm{L}$ nuclease-free water (Invitrogen) and the bacterial 16S rRNA genes were amplified by PCR using illustra PuReTaq Ready-To-Go PCR Beads (GE Healthcare) and the primers 27F (5'-AGAG TTTGATCMTGGCTCAG-3') [33] and 1100R (5'-AGGG TTGCGCTCGTT-3') modified from reference [34]. The PCR program had an initial denaturation at $95^{\circ} \mathrm{C}$ for $5 \mathrm{~min}$, followed by 30 cycles of $94{ }^{\circ} \mathrm{C}$ for $1 \mathrm{~min}, 56^{\circ} \mathrm{C}$ for $1 \mathrm{~min}$, $72{ }^{\circ} \mathrm{C}$ for $2 \mathrm{~min}$, followed by a final extension at $72{ }^{\circ} \mathrm{C}$ for $10 \mathrm{~min}$. Amplicon production and size were verified by electrophoresis in a $1 \%$ agarose gel. In our experience, lack of PCR amplification products results in no sequences. Therefore, negative controls obtained from DNA extraction and/or PCR amplification were not further processed and were not sequenced. The amplicons obtained were sent to Uppsala, Sweden, and used for the library preparation.

\section{Library Preparation and MiSeq Sequencing}

From the 16S rRNA gene PCR products obtained from the water samples, the V3-V4 region (Escherichia coli position 341-805) was amplified by a two-step PCR method. In the first step, the general bacterial primers $341 \mathrm{~F}$ (5'-CCTA
CGGGNGGCWGCAG-3) and 805R (5'-GACT ACHVGGGTATCTAATCC-3) [35] were used, which match approximately $90 \%$ of all bacterial sequences and cover all phyla in the Ribosomal Database Project release 10.25. Each DNA sample was individually PCR-amplified with illustra PuReTaq Ready-To-Go PCR Beads (GE Healthcare) by initial denaturation at $95{ }^{\circ} \mathrm{C}$ for $5 \mathrm{~min}$, followed by 20 cycles of $95{ }^{\circ} \mathrm{C}$ for $40 \mathrm{~s}, 53{ }^{\circ} \mathrm{C}$ for $40 \mathrm{~s}, 72{ }^{\circ} \mathrm{C}$ for $1 \mathrm{~min}$, followed by a final extension at $72{ }^{\circ} \mathrm{C}$ for $7 \mathrm{~min}$. The PCR products were analyzed by microchip electrophoresis using the MCE-202 MultiNA (Shimadzu) and diluted in nuclease-free water (Invitrogen) to a concentration of $0.1-1 \mathrm{ng} / \mu \mathrm{L}$. In the second step, 1 out of 50 flanking barcode sequence pairs was added to each sample (to be able to run samples in parallel) [36] using the same conditions as above, but only for 10 cycles of iteration. The PCR products were analyzed by microchip electrophoresis as before and pooled together, 50 differently barcoded samples per pool and $60 \mathrm{ng}$ per sample. In total, 6 pools of 50 samples each were created. Of the 300 samples, 48 samples belonged to this project and were randomly distributed over the 6 pools to avoid pool- sequencing bias. Each pool was purified using illlustra GFX PCR DNA and Gel Band Purification Kit (GE Healthcare) and eluted in $50 \mu \mathrm{L}$ nuclease-free water (Invitrogen). The pools were sent to the SNP\&SEQ Technology Platform in Uppsala, Sweden (www. sequencing.se) for further processing and sequencing. Sequencing libraries were prepared from $\sim 10 \mathrm{ng}$ of DNA using the ThruPLEX-FD Prep Kit (R40048-08, Rubicon Genomics) according to the manufacturer's instructions. The libraries were purified using AMPure XP beads and the quality evaluated using the 2200 TapeStation system (Agilent Technologies) and the D1000 Analysis ScreenTape assay. The adapter-ligated fragments were quantified by qPCR using the Library quantification kit for Illumina (KAPA Biosystems) on a StepOnePlus instrument (Applied Biosystems/Life technologies) prior to cluster generation and sequencing. The pooled DNA samples were paired-end sequenced with $300 \mathrm{bp}$ read length on the MiSeq system (Illumina) using the v3 chemistry according to the manufacturer's protocols. The raw MiSeq reads are available in the ENA database hosted by EBI under the accession number PRJEB25809. 


\section{Bioinformatics Analysis}

The paired-end reads were assembled and demultiplexed using Mothur (version 1.36.1) [37] resulting in 741,779 reads keeping sequences with fewer than two base differences between the primer portion of the read and the primer. Further analyses were performed by USEARCH (version 8.1.1861) [38]. Reads were filtered to remove low-quality reads using a maximum expected error threshold of one. The remaining sequences were de-replicated using full-length matching. Clustering of operational taxonomic units (OTUs) was performed using UPARSE [39] with a minimum identity of $97 \%$ and discarding singletons and chimeras. To make the OTU table, the reads before quality filtering and removal of singletons were mapped to the OTUs using a minimum identity of 0.97 to the representative sequence. Reads that were classified as chloroplasts were removed from the dataset manually in Microsoft Excel, leaving 416,420 reads in 154 OTUs for analysis. Reads from the three different water filters from the same site and sub-site were added together and treated as one sample in downstream analyses, yielding 16 samples (four sub-site samples for each of the four breeding sites). The taxonomic annotation of the OTUs was performed using the UTAX RDP train set 15 and a pretrained taxonomy confidence file for the sequence length 500. Taxonomical annotation was performed with a confidence threshold of 0.9 .

\section{Data Analysis}

All data analysis in $\mathrm{R}$ was performed using the R-software (version 3.3.3) [40] in R-studio (versions 1.1.383 and 1.1.456) [41]. To visualize the distribution of the reads among the samples, a bar chart was created in the Rpackage "ggplot2" [42] (Online Resource Fig. A.2). To normalize the reads between samples, the reads per OTU in the OTU table were converted into percentage of reads in each sample that belonged to each OTU. From rarefaction curves, it was seen that many samples reached a plateau suggesting that adequate sequencing depth was obtained for these samples. However, some samples did not level off suggesting insufficient sequencing depth, which can lead to an underestimation of bacterial diversity in these samples, though this was mainly seen for site 1 , which despite this had the highest observed alpha diversity (Online Resource Fig. A.3). Rarefaction curves were created in the R-package "vegan" [43]. To summarize and compare the bacterial community composition in the different An. darlingi breeding sites, bar charts showing the distribution of bacterial phyla, classes, and families were created. The distribution of bacteria at the different taxonomic levels was visualized in bar charts produced in the R-package "ggplot2" [42]. An in-house
Python script was used to extract the families present in the samples. The most common OTUs in all of the breeding sites were then identified and visualized by a bar chart produced by the same method as above. To look for differences in alpha diversity in the breeding sites, the OTU table was first rarefied to 10,073 reads per sample (based on the sample with the fewest reads) using the R-package "vegan" [43]. Observed and estimated (Chao1) species richness was calculated using the R-package "phyloseq" [44]. To illustrate the alpha diversity, box plots were created using the function "plot" in R. To visualize the similarities in bacterial community composition between the sites and the sub-sites (betadiversity), non-metric multidimensional scaling (NMDS) plots were created. These were made using the R-package "vegan" [43] on the Bray-Curtis dissimilarity index based on OTU abundance in the samples. To explore which OTUs differed between the bacterial communities in the breeding sites (beta-diversity), an indicator species analysis was performed using the R-package "labdsv" [45].

\section{Statistics}

For comparison of alpha diversity between the sites, analysis of variance (ANOVA) was first performed in R. This was based on normal distribution and homogeneity of variance of the samples, identified in R by Shapiro-Wilk's test and Bartlett's test, respectively. Following a statistically significant ANOVA result, pairwise comparisons using two-tailed $t$ tests with pooled standard deviation and $p$ value adjustment method Holm were performed in R. To compare the differences between the bacterial community compositions in the breeding sites, permutation-based analysis of variance (PERMANOVA) was performed with $10^{6}$ permutations and the beta-diversity measuring method Bray-Curtis in the Rpackage "vegan" [43]. Following a statistically significant PERMANOVA result, pairwise PERMANOVA was performed using the R-package "RVAideMemoire" [46] based on the Bray-Curtis dissimilarity matrix with $10^{6}$ permutations and $p$ value adjustment method Benjamini and Hochberg.

\section{Results}

\section{Bacterial Community Composition}

After sequencing the hypervariable V3-V4 region of the bacterial 16S rRNA gene and bioinformatics processing of the water samples from four An. darlingi breeding sites in Manaus, a total of 416,420 reads were left in 154 OTUs (the number of reads per sample was between 10,073 and 64,585, with an average of 26,026 reads per sample). The OTUs were classified into nine phyla with the top three phyla making up 
$98 \%$ of all the reads, Fig. 1a. Taken together, the data show that on average, $63 \%$ of all the reads belonged to Proteobacteria making it the most common phylum. The second and third most common phyla were Firmicutes and Bacteroidetes, making up $25 \%$ and $9 \%$, respectively. The nine phyla were divided into 14 classes with the top three classes making up $79 \%$ of the reads (Fig. 1b). The top three classes were Gammaproteobacteria, Bacilli, and Betaproteobacteria, which made up $42 \%, 24 \%$, and $12 \%$, respectively. In total, 38 families were identified. The bacterial families Enterobacteriaceae, Staphylococcaceae, and Pseudomonadaceae were most common, making up $27 \%$,
$24 \%$, and $12 \%$ of the reads, respectively (Fig. 1c). The separation of sequences for each sub-site is shown in Online Resource Fig. A.4.

Only 36 out of all the identified 154 OTUs were common in all breeding sites (Online Resource Fig. A.5), and even fewer were identified in all sub-sites in all breeding sites (10 out of 154 OTUs). However, 94\% of all the reads belonged to one of those 36 common OTUs. The relative frequencies of the most common OTUs found in all breeding sites show that the top three OTUs are Escherichia/Shigella (OTU283), Staphylococcus (OTU272), and Pseudomonas (OTU40, Fig. 2).
Fig. 1 Bacterial community composition in different Anopheles darlingi breeding sites in Manaus. a Bacterial community composition at phylum level, "Other" = unknown phylum. b Bacterial community composition at class level. Only classes making up $>0.1 \%$ in any sample are named, other classes present are clustered as "Other" together with unknown classes. c Bacterial community composition at family level. Only families making up $>1 \%$ in any sample are named, other families present are clustered as "Other" together with unknown families (a)

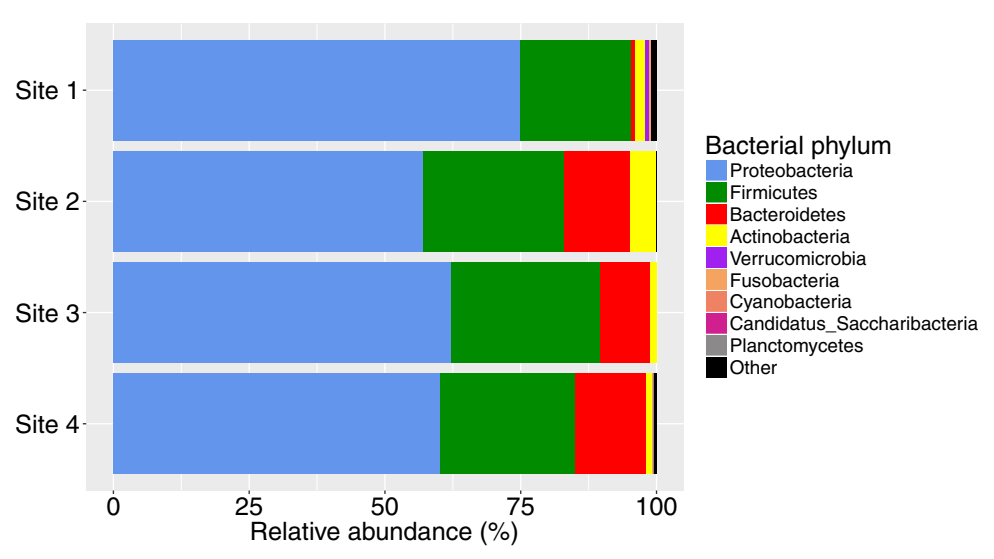

(b)

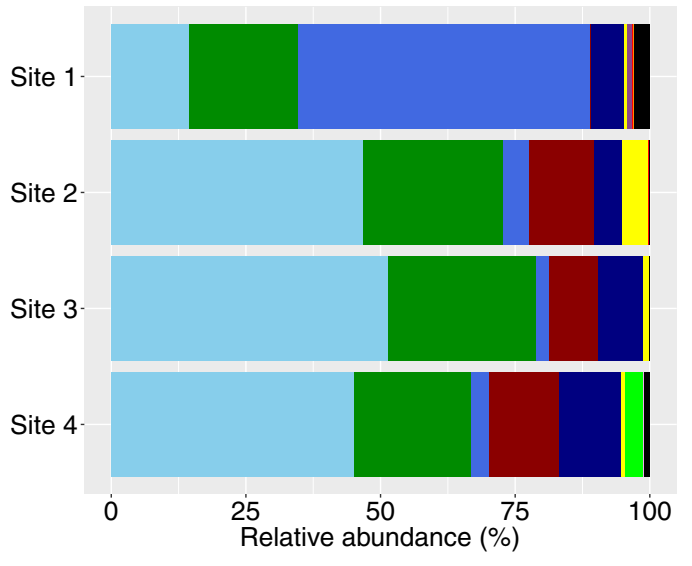

Bacterial class Gammaproteobacteria Bacilli

Betaproteobacteria Flavobacteriia Alphaproteobacteria Actinobacteria Clostridia Spartobacteria Sphingobacteriia Cytophagia Subdivision 3 of Verrucomicrobia Other

(c)

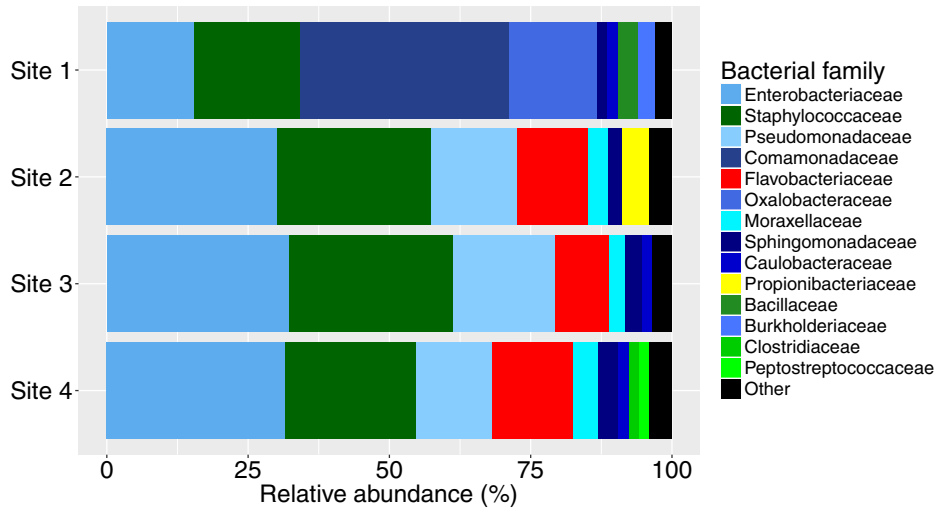




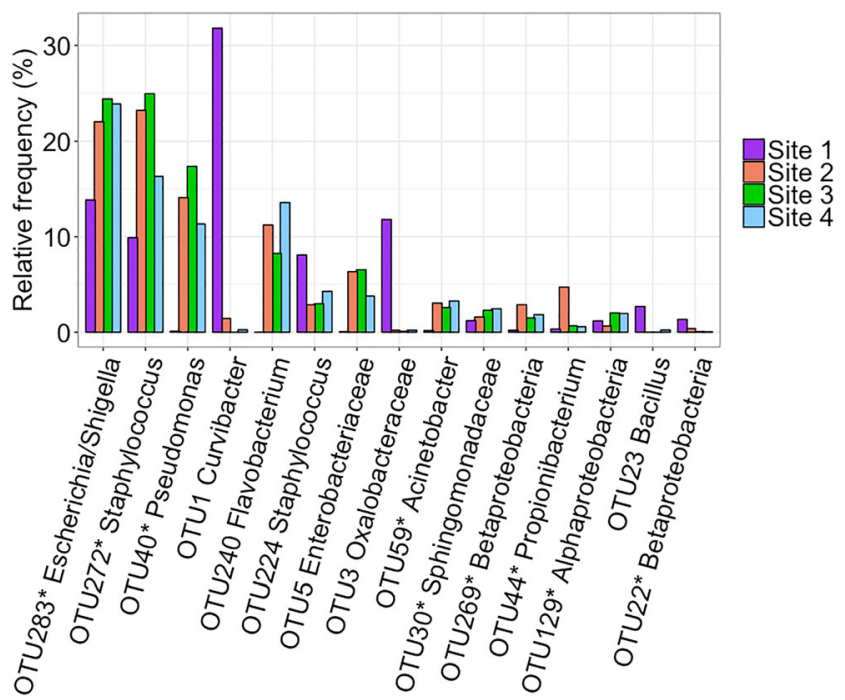

Fig. 2 Common operational taxonomic units (OTUs) found in all Anopheles darlingi breeding sites in Manaus. The top 15 most common OTUs are shown together with the identified taxonomy at the lowest available level. *OTUs that were found in all sub-sites

\section{Alpha Diversity}

Species richness, observed and estimated (Chaol), was compared between the four breeding sites (Fig. 3). Both indices were included to investigate both the actual number of OTUs observed and the number of OTUs estimated to exist from the abundance data by Chao1. Chao1 was included to account for OTUs that could be present in the breeding sites but not observed due to under sampling and too shallow sequencing depth. Observed species richness tended to differ between sites 1 and 3, but the difference was not statistically significant (Fig. 3a). However, when the species richness was estimated by Chao1, a statistically significant difference in alpha diversity appeared between breeding sites 1 and 3 ( $p=0.029$; Fig. $3 b)$. On average, 46 OTUs were observed per site and 52 OTUs were estimated per site by the Chao1 method.

\section{Bacterial Community Composition in Sub-sites}

To investigate the similarity of the bacterial community composition in the sub-sites from the four breeding sites, the OTUs from the sub-sites were compared, Fig. 4. When classifying the sub-sites according to which main breeding site they belonged to, it was found that the bacterial communities vary significantly between sites based on PERMANOVA $(p=$ $5 \times 10^{-6}$ ). Water samples that were taken from different subsites within the same main breeding site seemed to contain similar bacteria. When the sub-sites were compared by pairwise PERMANOVA based on the main breeding site they belonged to, it was found that all four sites were significantly different in bacterial community composition from each other except for sites 3 and 4 that were not significantly different, Table 2.

\section{Discriminatory OTUs}

To investigate which bacterial OTUs were driving the differences between the breeding sites, an indicator value analysis selecting discriminatory OTUs was performed according to Dufrene and Legendre [47] (Table 3). The OTUs with a significant indicator value for a specific breeding site are here referred to as "discriminatory OTUs". Indicator values range from 0 to 1 where the indicator value 1 means that an OTU is found in all samples in a defined group and that the specific OTU only is found in the defined group. Thirteen OTUs with high indicator values $(>0.7)$ were identified as discriminatory OTUs for breeding site 1 , many of which were identified as species within the order Burkholderiales. Sites 2-4 had only two or three identified discriminatory OTUs each. For sites 2 and 3, three of the five OTUs were associated with the order Actinomycetales. For site 4, the OTUs were associated with the order Clostridiales (Table 3).
Fig. 3 Alpha diversity in Anopheles darlingi breeding sites in Manaus. a Observed species richness and $\mathbf{b}$ estimated species richness, Chao1. *Difference in alpha diversity based on pairwise comparisons between breeding sites $(p$ value $<0.05)$. The samples were rarefied to 10,073 reads per sample before analysis (a)

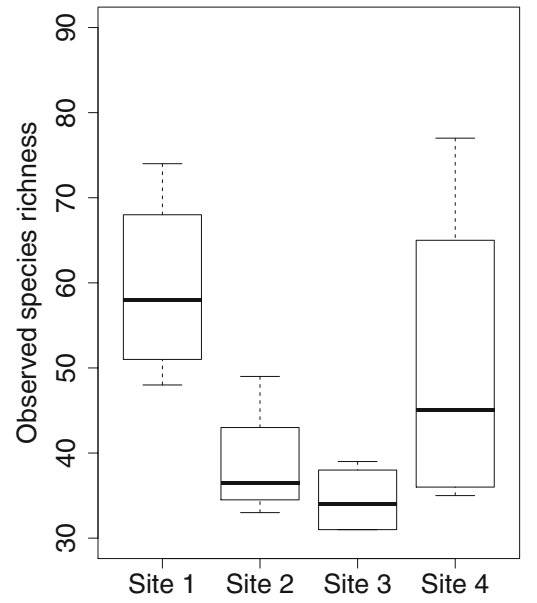

(b)

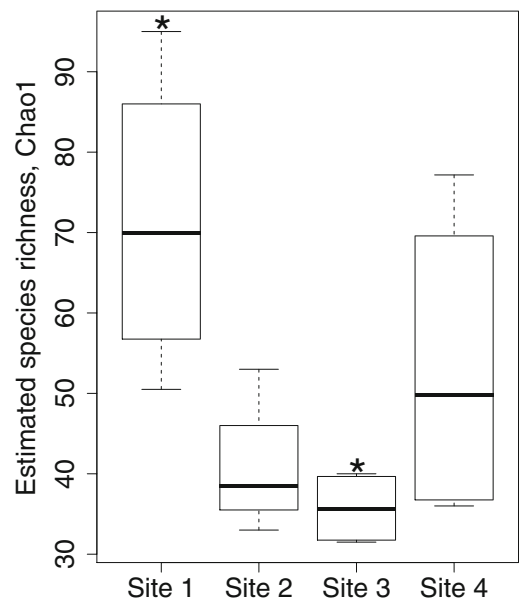




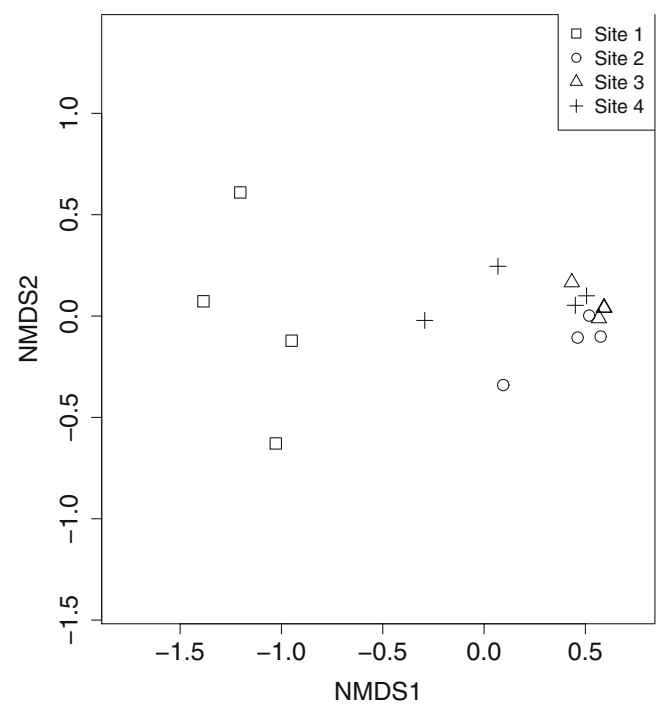

Fig. 4 Non-metric multidimensional scaling (NMDS) plots of water samples. The plots are based on all bacterial operational taxonomic units (OTUs) in the samples and separated by Anopheles darlingi breeding site. In each breeding site, four sub-sites were sampled. The points for two sub-sites from site 3 are overlaid. Stress value: 0.074

\section{Discussion}

In this study, we explored the bacterial community composition of An. darlingi breeding waters by characterizing and comparing the communities of four breeding sites in Manaus, Brazil, using 16S rRNA gene amplicon sequencing. We hypothesized that bacteria and the conditions they indicate would be similar in all sites because they all are characterized by large abundance of An. darlingi larvae. Although we found that $94 \%$ of the total number of reads belonged to 36 OTUs identified in all sites and that Proteobacteria and Firmicutes dominated in all sites, at lower taxonomic levels the bacterial composition diverged between sites. Three sites were similar in their bacterial composition, while one site differed significantly.

Previous studies on the microbiota of Anopheles breeding waters have mainly investigated those of Old World malaria vectors [17, 23-27]. Comparing our results from breeding waters of a New World malaria vector with those studies show that overall the same bacterial composition at phylum level

Table 2 Pairwise PERMANOVA comparing the beta diversity in Anopheles darlingi breeding sites in Manaus. Based on Bray-Curtis dissimilarity matrix with $10^{6}$, i.e. 1 million permutations and $p$ value adjustment method Benjamini and Hochberg. $P$ values for each comparison are shown

\begin{tabular}{llll}
\hline & Manaus 1 & Manaus 2 & Manaus 3 \\
\hline Manaus 2 & 0.034 & - & - \\
Manaus 3 & 0.034 & 0.034 & - \\
Manaus 4 & 0.034 & 0.034 & 0.057 \\
\hline
\end{tabular}

was found. The most common phyla in this study were Proteobacteria, Firmicutes, Bacteroidetes, and Actinobacteria. Proteobacteria were present in all of the above-mentioned studies. In Iran, Firmicutes was also identified in breeding sites for An. stephensi and An. maculipennis by 16S rRNA gene sequencing of isolated bacteria [26]. Three studies that use 454-pyrosequencing of 16S rRNA genes, which is a method more comparable to this study, obtained similar results. The four phyla that we identified as the most common in our breeding sites were also the most common in the surface layer of An. coluzzii and An. gambiae breeding waters in Cameroon [17]. These four phyla were also among the most common in Anopheles breeding waters on three Kenyan islands in Lake Victoria [25]. However, in their study Actinobacteria formed a smaller part of the total composition than in our study. Similarly, Wang et al. [24] identified the four phyla to be common in the surface layer of semi-natural breeding sites in Kenya. However, they found Cyanobacteria as the second most common phylum. In the study of domestic water-storage containers in India by Nilsson et al. [27], the same sequencing method (MiSeq) was used and the four most common phyla were the same as identified here. At class level, the bacterial composition was also similar with Gammaproteobacteria and Bacilli being among the most common in this study and also in the five studies of Anopheles breeding waters in the Old World. However, in the semi-natural breeding sites in Kenya, Alphaproteobacteria and Cyanobacteria were most abundant [24]. In the domestic water-storage containers in India, Alphaproteobacteria and Betaproteobacteria were also abundant [27], and on the Kenyan islands, Betaproteobacteria was most abundant [25]. This abundance of Betaproteobacteria was similar to our breeding site 1 that contained more Betaproteobacteria than Gammaproteobacteria (Fig. 1b). In a recent study by Bascuñán et al. [31] on New World Anopheles mosquitoes (An. nuneztovari and An. darlingi), the proportion of Gammaproteobacteria as similar in the breeding waters as compared to our data $(\sim 40 \%)$. However, this proportion increased during development likely reflecting the selection induced by the alkaline environment in the larval gut. At family level, the bacteria identified by Dinparast Djadid et al. [26] were Pseudomonadaceae, Moraxellaceae, Aeromonadaceae, Enterobacteriaceae, and Bacillaceae; of these all but Aeromonadaceae were identified in this study. The most common families identified by Wang et al. [24], Methylocystaceae, Cyanobacteria/FamilyII, and Acetobacteraceae, were different from the ones we identified. Taken together, the fact that by in large the same kind of bacteria are found in the breeding sites of different species of malaria mosquitoes from both the Old World and the New World suggests that, although separated by continents and several million years of evolution, the Anopheles mosquitoes prefer to breed in waters with similar characteristics. 
Table 3 Discriminatory OTUs identified by indicator species analysis for water from different Anopheles darlingi breeding sites in Manaus

\begin{tabular}{|c|c|c|c|c|c|c|}
\hline Site & OTU & Indval & $p$ value & Freq. & Taxonomy $^{\mathrm{a}}$ & Top hit ${ }^{\mathrm{b}}$ \\
\hline \multirow[t]{13}{*}{1} & OTU142 & 1.00 & 0.006 & 4 & p:Proteobacteria & Uncultured Leptothrix-99\% \\
\hline & OTU16 & 0.998 & 0.005 & 5 & p:Verrucomicrobia, c:Spartobacteria & $\begin{array}{l}\text { Uncultured bacterium } \\
\text { FukuN106-98\% }\end{array}$ \\
\hline & OTU38 & 0.966 & 0.009 & 6 & p:Actinobacteria & $\begin{array}{l}\text { Uncultured Micrococcineae } \\
-97 \%\end{array}$ \\
\hline & OTU3 & 0.958 & 0.007 & 12 & p:Proteobacteria, c:Betaproteobacteria, o:Burkholderiales, f:Oxalobacteraceae & \\
\hline & OTU1 & 0.949 & 0.003 & 8 & $\begin{array}{l}\text { p:Proteobacteria, c:Betaproteobacteria, o:Burkholderiales, } \\
\text { f:Comamonadaceae, g:Curvibacter }\end{array}$ & \\
\hline & OTU17 & 0.921 & 0.005 & 6 & $\begin{array}{l}\text { p:Proteobacteria, c:Betaproteobacteria, o:Burkholderiales, f:Burkholderiaceae, } \\
\text { g:Polynucleobacter }\end{array}$ & \\
\hline & OTU9 & 0.864 & 0.004 & 11 & p:Proteobacteria, c:Betaproteobacteria, o:Burkholderiales, f:Oxalobacteraceae & \\
\hline & OTU52 & 0.750 & 0.032 & 3 & $\mathrm{p}:$ Proteobacteria & - \\
\hline & OTU91 & 0.750 & 0.018 & 3 & $\mathrm{p}:$ Proteobacteria, c:Betaproteobacteria & $\begin{array}{l}\text { Uncultured } \\
\quad \text { Limnohabitans-99\% }\end{array}$ \\
\hline & OTU24 & 0.750 & 0.032 & 3 & $\begin{array}{l}\text { p:Bacteroidetes, c:Cytophagia, o:Cytophagales, f:Cytophagaceae, } \\
\text { g:Flectobacillus }\end{array}$ & \\
\hline & OTU94 & 0.750 & 0.027 & 3 & $\mathrm{p}:$ Proteobacteria, c:Betaproteobacteria & Deefgea-100\% \\
\hline & OTU22 & 0.733 & 0.022 & 16 & p:Proteobacteria, c:Betaproteobacteria & $\begin{array}{l}\text { Uncultured } \\
\text { Comamonadaceae- } 97 \%\end{array}$ \\
\hline & OTU160 & 0.702 & 0.029 & 7 & p:Proteobacteria, c:Betaproteobacteria, o:Burkholderiales & Curvibacter-99\% \\
\hline \multirow[t]{3}{*}{2} & OTU44 & 0.748 & 0.007 & 16 & $\begin{array}{l}\text { p:Actinobacteria, c:Actinobacteria, o:Actinomycetales, } \\
\text { f:Propionibacteriaceae, g:Propionibacterium }\end{array}$ & \\
\hline & OTU273 & 0.642 & 0.023 & 7 & $\begin{array}{l}\text { p:Actinobacteria, c:Actinobacteria, o:Actinomycetales, } \\
\text { f:Microbacteriaceae, g:Leifsonia }\end{array}$ & \\
\hline & OTU269 & 0.448 & 0.002 & 16 & p:Proteobacteria, c:Betaproteobacteria & $\begin{array}{l}\text { Curvibacter delicatus strain } \\
\quad \mathrm{N} 30-99 \%\end{array}$ \\
\hline \multirow[t]{2}{*}{3} & OTU83 & 0.565 & 0.028 & 12 & $\begin{array}{l}\text { p:Actinobacteria, c:Actinobacteria, o:Actinomycetales, f:Nocardiaceae, } \\
\mathrm{g}: \text { Rhodococcus }\end{array}$ & \\
\hline & OTU40 & 0.405 & 0.018 & 16 & $\begin{array}{l}\text { p:Proteobacteria, c:Gammaproteobacteria, o:Pseudomonadales, } \\
\text { f:Pseudomonadaceae, g:Pseudomonas }\end{array}$ & \\
\hline \multirow[t]{2}{*}{4} & OTU315 & 0.744 & 0.039 & 5 & $\begin{array}{l}\text { p:Firmicutes, c:Clostridia, o:Clostridiales, f:Clostridiaceae_1, } \\
\text { g:Clostridium_sensu_stricto }\end{array}$ & \\
\hline & OTU87 & 0.715 & 0.033 & 6 & $\begin{array}{l}\text { p:Firmicutes, c:Člostridia, o:Clostridiales, f:Peptostreptococcaceae, } \\
\text { g:Clostridium_XI }\end{array}$ & \\
\hline
\end{tabular}

OTU operational taxonomic unit, Indval indicator value, Freq. frequency, number of samples the OTU occurred in

${ }^{a} \mathrm{p}, \mathrm{c}, \mathrm{o}, \mathrm{f}$, and $\mathrm{g}$ refer to the taxonomic levels phylum, class, order, family, and genus, respectively

${ }^{\mathrm{b}}$ OTUs not identified to family level were compared to sequences in the database on the NCBI website using nucleotide BLAST with the representative sequence per OTU. The named bacterium (if any) with identity of $97 \%-100 \%$ is given

Of the bacteria common to all sites in this study (36 OTUs), several of the most abundant (Fig. 2) are connected to human habitats such as Escherichia/Shigella, Staphylococcus, and Pseudomonas indicating strong human influence on the microbiota. This is expected, as the sites are located near human habitations. Nevertheless, these bacteria have also been shown to appear frequently in other studies on mosquitoes and their breeding waters. For example, Dada et al. [48] reported from Thailand and Laos results where high abundance of $E$. coli was strongly correlated to the presence of Ae. aegypti mosquitoes. However, in their follow-up study, the correlation between abundance of $E$. coli and mosquitoes was not as strong [49]. For Pseudomonas, Chavshin et al. [50] showed that in Iranian An. culicifacies, these were the most common bacteria and that identical Pseudomonas 16S rRNA gene sequences were found in samples from locations far apart indicating a strong association with An. culicifacies. Although not yet convincingly shown, one could expect the bacteria in the surface microlayer to elicit odors that attract female mosquitoes. An. darlingi is considered a highly anthropophilic species breeding in close proximity to human settlements. In this regard, we speculate that the presence of the bacteria strongly connected to humans (Escherichia/Shigella, Staphylococcus, and Pseudomonas) could be used by the female mosquitoes as olfactory cues of where to oviposit.

Breeding site 1 (Portela) stands out as being different from the other sites at all taxonomic levels (Fig. 1), and also has the highest alpha diversity of the four sites with a significantly 
higher estimated richness than site 3 (Fig. 3). This higher alpha diversity might partly explain why many more discriminatory OTUs were identified for site 1 than for the other sites (Table 3). The difference of site 1 is also seen in the NMDS plot (Fig. 4) where all sub-sites from site 1 separate from the rest. At phylum level, Bacteroidetes occurs in very small numbers in site 1 , which consistently make up the third largest group in the other three sites. At a lower taxonomic level, it is seen that this group mainly is made up of Flavobacteriaceae and is also reflected in Fig. 2 where Flavobacterium is the fifth most common bacterium overall. One factor contributing to this difference in bacterial composition in breeding site 1 could be the collection date as this site was sampled earlier in the year than sites 2-4 (seasonal variations in bacterial composition in lakes have been observed [51]). However, the climate in Manaus from January to May 2013 showed little variability in terms of temperature and rainfall.

Several different species belonging to the order Burkholderiales were identified as descriptors of site 1. One discriminatory OTU not identified as Burkholderiales was identified as a species of Flectobacillus (Table 3). Flectobacillus (roseus) was recently found to be a fish pathogen [52], and as site 1 receives a stream with fish, this might explain the presence of Flectobacillus here. Otherwise, site 1 stands out as containing several bacterial genera previously isolated from and associated with fresh or brackish water sources (Flectobacillus, Curvibacter, and Polynucleobacter) [53-55]. This finding could indicate that the water at site 1 was less affected by human settlements. One of the discriminatory species for site 2, Propionibacterium, could indicate human or animal presence as it is commonly described as a commensal part of the skin microbiota in both humans and animals [56].

An. darlingi was abundant in the breeding sites investigated here. Although the breeding sites had different levels of vegetation and the amount of fish varied from no fish at all to the sites being fish tanks, An. darlingi larvae thrived in all of them. Previously, several studies have investigated environmental characteristics associated with An. darlingi larvae and found that they prefer large, deep, and clear water bodies, such as lakes, swamps, and rivers [21]. Also, fishponds have been shown to function as important breeding sites for An. darlingi $[57,58]$ with four times more larvae than natural water bodies [57]. Even though some environmental characteristics have been associated with An. darlingi larvae and An. darlingi was shown to be the least tolerant of three Anopheles species to habitat types other than their own typical habitat [59], they exist in many habitat types [60]. An. darlingi density has also been found to be higher in larval habitats closer to human habitations [61] and to be good at adapting to environments modified by human development [21]. This suggests that $A n$. darlingi is opportunistic, and though it might prefer some types of habitats, it can breed in water with different types of bacteria as shown in this study.

\section{Conclusions}

Most cases of malaria on the American continent occur in the Amazon region where An. darlingi is the most important vector [62]. We hypothesized that bacteria and the conditions they indicate would be similar in all locations as they all are characterized by large abundance of An. darlingi larvae. However, based on our findings of diverging bacterial communities, we draw the conclusion that An. darlingi can develop in breeding waters with different surface-water bacteria although the common microbiota found in all breeding sites might contribute to the suitable habitat. Bacteria in mosquito breeding-waters have been shown to affect oviposition by adult mosquitoes and development of larvae as well as being taken up by mosquitoes and forming part of their gut microbiota [8-17]. Therefore, this new information on bacteria in An. darlingi breeding waters could be useful in vector- and malariacontrol strategies based on natural mosquito- and parasiteinhibitory effects of the bacteria, or by genetic modification of the bacteria to prevent transmission of malaria parasites.

Acknowledgments Sequencing was performed by the SNP\&SEQ Technology Platform in Uppsala. The facility is part of the National Genomics Infrastructure (NGI) Sweden and Science for Life Laboratory. The SNP\&SEQ Platform is also supported by the Swedish Research Council and the Knut and Alice Wallenberg Foundation.

Funding This study was funded by the Swedish Research Council (grant number 348-2012-622).

\section{Compliance with Ethical Standards}

Conflict of Interest The authors declare that they have no conflict of interest.

Open Access This article is distributed under the terms of the Creative Commons Attribution 4.0 International License (http:// creativecommons.org/licenses/by/4.0/), which permits unrestricted use, distribution, and reproduction in any medium, provided you give appropriate credit to the original author(s) and the source, provide a link to the Creative Commons license, and indicate if changes were made.

\section{References}

1. Malhi Y, Roberts JT, Betts RA, Killeen TJ, Li WH, Nobre CA (2008) Climate change, deforestation, and the fate of the Amazon. Science (New York, NY) 319:169-172. https://doi.org/10.1126/ science.1146961

2. Fierer N (2017) Embracing the unknown: disentangling the complexities of the soil microbiome. Nat Rev Microbiol 15:579-590. https://doi.org/10.1038/nrmicro.2017.87

3. Battin TJ, Besemer K, Bengtsson MM, Romani AM, Packmann AI (2016) The ecology and biogeochemistry of stream biofilms. Nat Rev Microbiol 14:251-263. https://doi.org/10.1038/nrmicro.2016. 15

4. Lloyd-Price J, Mahurkar A, Rahnavard G, Crabtree J, Orvis J, Hall AB, Brady A, Creasy HH, McCracken C, Giglio MG, McDonald D, Franzosa EA, Knight R, White O, Huttenhower C (2017) 
Strains, functions and dynamics in the expanded human microbiome project. Nature 550:61-66. https://doi.org/10.1038/ nature23889

5. Zaneveld JR, McMinds R, Vega Thurber R (2017) Stress and stability: applying the Anna Karenina principle to animal microbiomes. Nat Microbiol 2:17121. https://doi.org/10.1038/nmicrobiol. 2017.121

6. Naylor D, DeGraaf S, Purdom E, Coleman-Derr D (2017) Drought and host selection influence bacterial community dynamics in the grass root microbiome. ISME J 11:2691-2704. https://doi.org/10. 1038/ismej.2017.118

7. Foo JL, Ling H, Lee YS, Chang MW (2017) Microbiome engineering: current applications and its future. Biotechnol J 12. https://doi. org/10.1002/biot.201600099

8. Merritt RW, Dadd RH, Walker ED (1992) Feeding behavior, natural food, and nutritional relationships of larval mosquitoes. Annu Rev Entomol 37:349-376. https://doi.org/10.1146/annurev.en.37. 010192.002025

9. Wotton RS, Chaloner DT, Yardley CA, Merritt RW (1997) Growth of Anopheles mosquito larvae on dietary microbiota in aquatic surface microlayers. Med Vet Entomol 11:65-70

10. Rozeboom LE (1935) The relation of bacteria and bacterial filtrates to the development of mosquito larvae. Am J Epidemiol 21:167-179

11. Toure AM, Mackey AJ, Wang ZX, Beier JC (2000) Bactericidal effects of sugar-fed antibiotics on resident midgut bacteria of newly emerged anopheline mosquitoes (Diptera: Culicidae). J Med Entomol 37:246-249

12. Coon KL, Vogel KJ, Brown MR, Strand MR (2014) Mosquitoes rely on their gut microbiota for development. Mol Ecol 23:27272739. https://doi.org/10.1111/mec. 12771

13. Sumba LA, Guda TO, Deng AL, Hassanali A, Beier JC, Knols BGJ (2004) Mediation of oviposition site selection in the African malaria mosquito Anopheles gambiae (Diptera: Culicidae) by semiochemicals of microbial origin. Int J Trop Insect Sci 24:260-265. https:// doi.org/10.1079/IJT200433

14. Ponnusamy L, Xu N, Nojima S, Wesson DM, Schal C, Apperson CS (2008) Identification of bacteria and bacteria-associated chemical cues that mediate oviposition site preferences by Aedes aegypti. Proc Natl Acad Sci 105:9262-9267. https://doi.org/10.1073/pnas. 0802505105

15. Huang J, Miller JR, Chen S-C, Vulule JM, Walker ED (2006) Anopheles gambiae (Diptera: Culicidae) oviposition in response to agarose media and cultured bacterial volatiles. J Med Entomol 43:498-504

16. Boissiere A, Tchioffo MT, Bachar D, Abate L, Marie A, Nsango SE, Shahbazkia HR, Awono-Ambene PH, Levashina EA, Christen R, Morlais I (2012) Midgut microbiota of the malaria mosquito vector Anopheles gambiae and interactions with Plasmodium falciparum infection. PLoS Path 8:e1002742. https://doi.org/10. 1371/journal.ppat.1002742

17. Gimonneau G, Tchioffo MT, Abate L, Boissière A, AwonoAmbéné PH, Nsango SE, Christen R, Morlais I (2014) Composition of Anopheles coluzzii and Anopheles gambiae microbiota from larval to adult stages. Infect Genet Evol 28:715-724. https://doi.org/10.1016/j.meegid.2014.09.029

18. Ramirez JL, Short SM, Bahia AC, Saraiva RG, Dong Y, Kang S, Tripathi A, Mlambo G, Dimopoulos G (2014) Chromobacterium Csp_P reduces malaria and dengue infection in vector mosquitoes and has entomopathogenic and in vitro anti-pathogen activities. PLoS Path 10:e1004398. https://doi.org/10.1371/journal.ppat. 1004398

19. Cirimotich CM, Dong Y, Clayton AM, Sandiford SL, Souza-Neto JA, Mulenga M, Dimopoulos G (2011) Natural microbe-mediated refractoriness to Plasmodium infection in Anopheles gambiae. Science (New York, NY) 332:855-858. https://doi.org/10.1126/ science. 1201618
20. Riehle MA, Jacobs-Lorena M (2005) Using bacteria to express and display anti-parasite molecules in mosquitoes: current and future strategies. Insect Biochem Mol Biol 35:699-707. https://doi.org/ 10.1016/j.ibmb.2005.02.008

21. Hiwat H, Bretas G (2011) Ecology of Anopheles darlingi Root with respect to vector importance: a review. Parasit Vectors 4:177. https://doi.org/10.1186/1756-3305-4-177

22. WHO (2018) World Malaria Day 2018: Ready to beat malaria. http:/www.who.int/malaria/media/world-malaria-day-2018/en/. Accessed 5 April 2018

23. Briones AM, Shililu J, Githure J, Novak R, Raskin L (2008) Thorsellia anophelis is the dominant bacterium in a Kenyan population of adult Anopheles gambiae mosquitoes. The ISME J 2:74 82. https://doi.org/10.1038/ismej.2007.95

24. Wang Y, Gilbreath 3rd TM, Kukutla P, Yan G, Xu J (2011) Dynamic gut microbiome across life history of the malaria mosquito Anopheles gambiae in Kenya. PLoS One 6:e24767. https://doi. org/10.1371/journal.pone.0024767

25. Onchuru TO, Ajamma YU, Burugu M, Kaltenpoth M, Masiga D, Villinger J (2016) Chemical parameters and bacterial communities associated with larval habitats of Anopheles, Culex and Aedes mosquitoes (Diptera: Culicidae) in western Kenya. Int J Trop Insect Sci 36:146-160. https://doi.org/10.1017/S1742758416000096

26. Dinparast Djadid N, Jazayeri H, Raz A, Favia G, Ricci I, Zakeri S (2011) Identification of the midgut microbiota of An. stephensi and An. maculipennis for their application as a paratransgenic tool against malaria. PLoS One 6:e28484. https://doi.org/10.1371/ journal.pone.0028484

27. Nilsson LKJ, Sharma A, Bhatnagar RK, Bertilsson S, Terenius O (2018) Presence of Aedes and Anopheles mosquito larvae is correlated to bacteria found in domestic water-storage containers. FEMS Microbiol Ecol 94:fiy058. https://doi.org/10.1093/femsec/fiy058

28. Rejmankova E, Harbin-Ireland A, Lege M (2000) Bacterial abundance in larval habitats of four species of Anopheles (Diptera: Culicidae) in Belize, Central America. J Vector Ecol 25:229-239

29. Terenius O, De Oliveira CD, Pinheiro WD, Tadei NP, James AA, Marinotti O (2008) 16S rRNA gene sequences from bacteria associated with adult Anopheles darlingi (Diptera : Culicidae) mosquitoes. J Med Entomol 45:172-175. https://doi.org/10.1603/00222585(2008)45[172:Srgsfb]2.0.Co;2

30. Arruda A, Ferreira GS, Lima NCD, dos Santos A, Custodio MGF, Benevides-Matos N, Ozaki LS, Stabeli RG, Silva AA (2017) A simple methodology to collect culturable bacteria from feces of Anopheles darlingi (Diptera: Culicidae). J Microbiol Methods 141:115-117. https://doi.org/10.1016/j.mimet.2017.08.004

31. Bascunan P, Nino-Garcia JP, Galeano-Castaneda Y, Serre D, Correa MM (2018) Factors shaping the gut bacterial community assembly in two main Colombian malaria vectors. Microbiome 6:148. https:// doi.org/10.1186/s40168-018-0528-y

32. Becker N (2010) Mosquitoes and their control. Springer, Heidelberg

33. Fukatsu T, Nikoh N (1998) Two intracellular symbiotic bacteria from the mulberry psyllid Anomoneura mori (Insecta, Homoptera). Appl Environ Microbiol 64:3599-3606

34. Sawada H, Ieki H, Oyaizu H, Matsumoto S (1993) Proposal for rejection of Agrobacterium tumefaciens and revised descriptions for the genus Agrobacterium and for Agrobacterium radiobacter and Agrobacterium rhizogenes. Int J Syst Bacteriol 43:694-702. https://doi.org/10.1099/00207713-43-4-694

35. Herlemann DPR, Labrenz M, Jurgens K, Bertilsson S, Waniek JJ, Andersson AF (2011) Transitions in bacterial communities along the $2000 \mathrm{~km}$ salinity gradient of the Baltic Sea. ISME J 5:15711579. https://doi.org/10.1038/ismej.2011.41

36. Sinclair L, Osman OA, Bertilsson S, Eiler A (2015) Microbial community composition and diversity via $16 \mathrm{~S}$ rRNA gene amplicons: 
evaluating the Illumina platform. PLoS One 10:e0116955. https:// doi.org/10.1371/journal.pone.0116955

37. Schloss PD, Westcott SL, Ryabin T, Hall JR, Hartmann M, Hollister EB, Lesniewski RA, Oakley BB, Parks DH, Robinson CJ, Sahl JW, Stres B, Thallinger GG, Van Horn DJ, Weber CF (2009) Introducing mothur: open-source, platform-independent, community-supported software for describing and comparing microbial communities. Appl Environ Microbiol 75:7537-7541. https://doi.org/10.1128/aem.01541-09

38. Edgar RC (2010) Search and clustering orders of magnitude faster than BLAST. Bioinformatics 26:2460-2461. https://doi.org/10. 1093/bioinformatics/btq461

39. Edgar RC (2013) UPARSE: highly accurate OTU sequences from microbial amplicon reads. Nat Methods 10:996-998. https://doi. org/10.1038/nmeth.2604 http://www.nature.com/nmeth/journal/ v10/n10/abs/nmeth.2604.html - supplementary-information

40. R Core Team (2017) R: a language and environment for statistical computing. R Foundation for Statistical Computing, Vienna

41. RStudio Team (2015) RStudio: integrated development for R. RStudio, Inc., Boston, MA

42. Wickham H (2009) ggplot2: elegant graphics for data analysis. Springer-Verlag New York

43. Oksanen J, Blanchet FG, Friendly M, Kindt R, Legendre P, McGlinn D, Minchin PR, O'Hara RB, Simpson GL, Solymos P, Stevens MHH, Szoecs E, Wagner H (2017) Vegan: community ecology package. R package version 2.4-3. https://CRAN.Rproject.org/package=vegan

44. McMurdie PJ, Holmes S (2013) Phyloseq: an R package for reproducible interactive analysis and graphics of microbiome census data. PLoS One 8:e61217. https://doi.org/10.1371/journal.pone. 0061217

45. Roberts DW (2016) Labdsv: ordination and multivariate analysis for ecology. R package version 1.8-0. https://CRAN.R-project.org/ package $=$ labdsv

46. Hervé M (2018) RVAideMemoire: testing and plotting procedures for biostatistics. R package version $0.9-70$

47. Dufrene M, Legendre P (1997) Species assemblages and indicator species: the need for a flexible asymmetrical approach. Ecol Monogr 67:345-366

48. Dada N, Vannavong N, Seidu R, Lenhart A, Stenstrom TA, Chareonviriyaphap T, Overgaard HJ (2013) Relationship between Aedes aegypti production and occurrence of Escherichia coli in domestic water storage containers in rural and sub-urban villages in Thailand and Laos. Acta Trop 126:177-185. https://doi.org/10. 1016/j.actatropica.2013.02.023

49. Dada N, Jumas-Bilak E, Manguin S, Seidu R, Stenstrom T-A, Overgaard HJ (2014) Comparative assessment of the bacterial communities associated with Aedes aegypti larvae and water from domestic water storage containers. Parasite Vector 7:391. https://doi. org/10.1186/1756-3305-7-391

50. Chavshin AR, Oshaghi MA, Vatandoost H, Pourmand MR, Raeisi A, Terenius O (2014) Isolation and identification of culturable bacteria from wild Anopheles culicifacies, a first step in a paratransgenesis approach. Parasite Vector 7:419. https://doi.org/ 10.1186/1756-3305-7-419

51. Eiler A, Heinrich F, Bertilsson S (2012) Coherent dynamics and association networks among lake bacterioplankton taxa. ISME J 6: 330-342. https://doi.org/10.1038/ismej.2011.113
52. Adikesavalu H, Patra A, Banerjee S, Sarkar A, Abraham TJ (2015) Phenotypic and molecular characterization and pathology of Flectobacillus roseus causing flectobacillosis in captive held carp Labeo rohita (Ham.) fingerlings. Aquacult 439:60-65. https://doi. org/10.1016/j.aquaculture.2014.12.036

53. Sheu SY, Liu LP, Chen WM (2017) Flectobacillus pallidus sp. nov., isolated from a freshwater spring. Int J Syst Evol Microbiol 67: 1126-1132. https://doi.org/10.1099/ijsem.0.001774

54. Ahmed W, Staley C, Hamilton KA, Beale DJ, Sadowsky MJ, Toze S, Haas CN (2017) Amplicon-based taxonomic characterization of bacteria in urban and peri-urban roof-harvested rainwater stored in tanks. Sci Total Environ 576:326-334. https://doi.org/10.1016/j. scitotenv.2016.10.090

55. Hahn MW, Huymann LR, Koll U, Schmidt J, Lang E, Hoetzinger M (2017) Polynucleobacter wuianus sp. nov., a free-living freshwater bacterium affiliated with the cryptic species complex PnecC. Int J Syst Evol Microbiol 67:379-385. https://doi.org/10.1099/ ijsem.0.001637

56. Byrd AL, Belkaid Y, Segre JA (2018) The human skin microbiome. Nat Rev Microbiol 16:143-155. https://doi.org/10.1038/nrmicro. 2017.157

57. dos Reis IC, Codeco CT, Degener CM, Keppeler EC, Muniz MM, de Oliveira FGS, Cortes JJC, Monteiro AD, de Souza CAA, Rodrigues FCM, Maia GR, Honorio NA (2015) Contribution of fish farming ponds to the production of immature Anopheles spp. in a malaria-endemic Amazonian town. Malar J 14:Artn 452. https://doi.org/10.1186/S12936-015-0947-1

58. Nobre Arcos A, da Silva Ferreira FA, da Cunha HB, Tadei WP (2018) Characterization of artificial larval habitats of Anopheles darlingi (Diptera: Culicidae) in the Brazilian Central Amazon. Revista Brasileira de Entomologia 62:267-274

59. Grieco JP, Rejmankova E, Achee NL, Klein CN, Andre R, Roberts D (2007) Habitat suitability for three species of Anopheles mosquitoes: larval growth and survival in reciprocal placement experiments. J Vector Ecol 32:176-187. https://doi.org/10.3376/10811710(2007)32[176:Hsftso]2.0.Co;2

60. Villarreal-Trevino C, Penilla-Navarro RP, Vazquez-Martinez MG, Moo-Llanes DA, Rios-Delgado JC, Fernandez-Salas I, Rodriguez AD (2015) Larval habitat characterization of Anopheles darlingi from its northernmost geographical distribution in Chiapas, Mexico. Malar J 14:517. https://doi.org/10.1186/S12936-0151037-0

61. Sanchez-Ribas J, Oliveira-Ferreira J, Gimnig JE, Pereira-Ribeiro C, Santos-Neves MSA, Silva-do-Nascimento TF (2017) Environmental variables associated with anopheline larvae distribution and abundance in Yanomami villages within unaltered areas of the Brazilian Amazon. Parasite Vector 10:571. https://doi.org/10. 1186/S13071-017-2517-6

62. Recht J, Siqueira AM, Monteiro WM, Herrera SM, Herrera S, Lacerda MVG (2017) Malaria in Brazil, Colombia, Peru and Venezuela: current challenges in malaria control and elimination. Malar J 16:273. https://doi.org/10.1186/s12936-017-1925-6 